Article

\title{
Citizen-Scholars: Social Media and the Changing Nature of Scholarship
}

\author{
Amy L. Chapman * (i) and Christine Greenhow \\ Department of Counseling, Educational Psychology, and Special Education Michigan State University, \\ East Lansing, MI 48824, USA; greenhow@msu.edu \\ * Correspondence: chapm276@msu.edu; Tel.: +1-908-268-3765
}

Received: 1 December 2018; Accepted: 28 January 2019; Published: 1 February 2019

\begin{abstract}
Research is rarely created for private use; researchers publish their work so that others can read and use it, to advance the collective understanding of a field and impact people's lives. Yet traditional approaches to scholarship, which emphasize publication in subscription-based rather than open access journals, inhibit not only the dissemination of research but also its usefulness, particularly outside of academia. Across all fields, scholars, educators, and members of the public benefit from scholarship which is easily accessible. Open science and public, social scholarship can break down these barriers to accessibility and utility. In this age which calls for a more informed citizenry, the use of social media to share and promote discussion of research could change not only the nature of scholarly communication but also the nature of scholarship and scholars' roles. In this conceptual article, we argue that practicing public, social scholarship and increasing the use of social media to promote scholarship are the civic responsibility of citizen-scholars, so that research becomes more widely accessible, shareable, and usable in the public sphere.
\end{abstract}

Keywords: social media; scholarship; citizen; civic engagement; research; open science; public scholarship

\section{Introduction}

In the age of social media, the nature of scholarship has begun to shift toward greater openness and transparency and the utilization of various multimedia formats [1-3]. Historically, the traditional model of scholarship has been structured around communities of scholars, grouped into institutions, whose research is disseminated through academic journals, available via institutional or individual paid subscriptions. This approach has limited public access to research. Recent calls for open science, or the idea of openly sharing scientific knowledge as early as possible in the discovery process can be seen as an invitation to promote wider consumption of research through publication in accessible formats or open access journals $[4,5]$. It can also be seen as a move toward re-envisioning the role of scholars, especially in terms of how scholars contribute to public discourse and the role that technologies like social media might play in facilitating this contribution. Advancing the knowledge base and participating in public discourse through scholarship are two ways in which scholars contribute to civic life. Social media may assist scholars in these practices, enabling them to share work; interact with a broad audience; and become citizen-scholars, generating research with a commitment to the improvement of society. In this conceptual article, we argue that performing open, public, and social scholarship using social media is the civic responsibility of today's citizen-scholars, so that research becomes more accessible, shareable, and usable in the public sphere. Next, we present a short overview of the traditional model of scholarship, followed by brief descriptions of three converging trends in scholarly practices: open science, public scholarship, and social scholarship, which foreground our discussion of the responsibilities and practices of citizen-scholars in the age of social media. 


\section{Traditional Model of Scholarship}

In the traditional model of scholarship, scholars from different disciplines convene in a common physical place (e.g., university or college) and conduct research, which is disseminated through the classes they teach on campus and through publications. Ideally, scholarship is grounded in openness; being transparent about one's research allows others to see that it is legitimate, and to corroborate or dispute it through subsequent research. However, criteria for funding and publication have not typically encouraged open science; they do not promote the sharing of materials, software, codes, or data sets between researchers, nor do they promote the publication of findings without statistically significant results [6]. In addition, research findings that are published are often inaccessible to many, given the high costs of academic journals.

Although the concept of the university is a relatively modern construct, the idea that there was a place where scholars gathered to teach and students gathered to learn is considerably older. Though there have been different understandings and purposes of universities over time-from religious institutions which prepared students for religious life, to government-run centers of learning where graduates became members of polite society, to practical institutions intended to prepare students to enter agricultural or mechanical professions-research conducted and classes taught at universities have long been shaped by constraints [7]. Whether their purpose was religious, secular, or practical, universities were the centers of knowledge that was given out to particular people for a particular purpose.

The constraints of this university model, with its control of scholarship production and knowledge flows, benefitted some students, such as those who wanted to train in a specific vocational field or to pursue religious life. However, not all people who seek to pursue additional education are able to attend a university; cost, location, or the amount of time needed to pursue a degree, among other factors, are prohibitive for many prospective students. With traditional forms of scholarship, students are limited in their higher education choices by the campus-based model. The ways in which research has historically been disseminated (e.g., through teaching) advantages students who have the desire and means to attend a university while disadvantaging others.

In addition to limits imposed by institutional contexts, funders and publishing outlets also constrain meaningful, comprehensive scholarship dissemination and in turn, public discourse. Research, particularly in the sciences, is built upon openness and transparency [8]. Research is conducted, ideally, in such a way that others can follow the work that was done and the conclusions that have been drawn. However, this openness is neglected, sometimes to the point of being disincentivized, when it comes to the dissemination of research. Sources of funding and publication outlets seek to support and publish new research with significant findings, even though research which corroborates prior research or research with null findings can be as valuable in making sense of the world [8]. This contributes to the development of scholars who do not have a complete view of research in their field, as publications skew towards statistically significant results, and data, materials, methods, or codes are not shared.

\section{Open Science}

In light of these limitations above, the traditional, campus-based model of scholarship no longer remains the only viable model. From university-organized electronic communications, such as online or hybrid courses, to informal and independent learning made possible and accessible through online resources, the internet has shaped when, where, and with whom learning and teaching occur [9]. In addition to making it possible for students who are interested in higher education to have options beyond coming to campus to learn, the internet has created a space for open science. Open science is a model of scholarship in which all aspects of the research process are open and transparent. As Masuzzo and Martens argue: 
The overall goal of open science is to accelerate scientific progress and discoveries and to turn these discoveries into benefits for all. An essential part of this process is therefore to guarantee that all sorts of scientific outputs are publicly available, easily accessible, and discoverable for others to use, re-use, and build upon. [4] (p. 1)

Thus, in enacting open science, scholars make their methods, codes, and materials, as well as their research results, available to the public at no cost. With open science, the expectations and requirements of publication shift from only publishing new, statistically significant research to publishing rigorously conducted research that can include studies which corroborate prior research or have null findings.

Furthermore, the call for open science includes more than a call for sharing research tools, data sets, and findings. Some open access journals, in addition to providing free access to the research that they publish, also work to support open science in other ways. For example, the University of Huddersfield Press has sought to actively engage the scholarly community via social media to support researcher interactions and disseminate research publications beyond academia [10]. The press uses Facebook and Twitter to connect authors to each other, to share information about its processes, and to increase the reach, or potential audience, of its publications [10]. Additionally, Huddersfield Press seeks to develop the next generation of scholars, offering funds to provide early career scholars with time for writing and editing and inviting them to writing retreats offered by the publishing house [10]. This investment in future scholars is intended to illuminate the process of accessible academic publishing, provide them with skills to build their body of work, and increase the amount of open access research [10].

In addition to utilizing open access publishing outlets, some in the research community have called for the elimination of publishing research results in academic journals entirely [11]. Instead of publishing results at the end of the research process, Hartgerink and van Zelst argue that each step of research should be communicated separately as it is completed, allowing each step to be evaluated and refined before moving on to the next step. Elements of the research process, they argue, should be made public through networked modules with open access, which would allow not only for the connection of the pieces of a particular study but also for connection of those elements to other, related studies [11]. This method of communicating research processes and outputs would also allow for the inclusion of methods, codes, and materials, for which traditional academic journal formats typically do not have space [11].

The open science model of scholarship has several potential challenges and benefits over the traditional model [12]. Challenges to enacting open science, especially involving social media, include the risk of ideas being stolen, the difficulties of getting credit for work published primarily on social media, disagreement about standards and incentives for conducting open science, and the time and effort needed to learn how to use social media tools to create open access networked models or to initiate and sustain social media accounts for open science purposes [13]. On the other hand, those in favor of open science argue that it breaks down barriers: between scholars who are researching similar questions, between scholars from different disciplines, and between scholars and learners. If open science practices were normative (e.g., open publishing or networked modules that include data sets, protocols, and findings shared with other researchers), scholars who are researching the same topics or asking similar questions could become knowledgeable of others' work and build on it. In this way, open science could foster a more accurate and comprehensive knowledge base in a discipline, including knowledge of successful and failed interventions. Additionally, complex societal problems typically require interdisciplinary research teams. Open science could spark more boundary-crossing and productive collaborations at the intersection of disciplines, where increased access to data sets make data-sharing and multi-method analyses from diverse perspectives possible. Open science can also increase the ability of learners to access research, especially for those not affiliated with a university, or who cannot or do not want to pay for journal access. Members of the public seeking current research on a particular topic face fewer barriers through open science. Finally, open science benefits scholars, as papers published in open journals are more likely to be cited and mentioned in 
the media [12]. Together, these affordances of open science contribute to a multiplicity of paths for the acceleration, dissemination, and usefulness of "discoveries into benefits for all" [4].

\section{Public Scholarship}

While calls for open science are relatively recent in academia, the idea that scholarship should be public is not new. John Dewey, in the early 1900s, argued that scholars should interact with the public in order to identify, shed light on, and help solve societal problems [14]. Moreover, Dewey thought that science could be most helpful in alleviating social problems and contributing to progress through robust public inquiry [14]. For Dewey, public inquiry was the way in which scholarship was useful to all, and not limited to particular fields where new research might trickle down to people who might use it [14].

A more contemporary definition of public scholarship expands upon Dewey's associations between the process and products of research, education, and their potential impacts on democratic values and civic action. Imagining America, a higher education consortium in the United States dedicated to public scholarship in the arts, humanities, and design, defines public scholarship as "scholarly or creative activity integral to a faculty member's academic area ... [that] contributes to the public good and yields artifacts of public and intellectual value" [15] (p. 1, emphasis added). Public scholarship includes the diverse ways in which scholars and their community partners communicate knowledge. In public scholarship, the purpose of both the research and the ways in which it is circulated is to contribute to education and civic life [15]. This goal can be achieved through a variety of research or creative activity which enhances teaching and learning, promotes an informed citizenry and various methods of civic education, increases awareness of civic responsibility and encourages civic engagement, and investigates and creates solutions to societal problems [15].

With this definition, public scholarship is seen not only through the lens of open science; but is understood to contribute to the public good. There are a variety of ways in which scholars can engage in public scholarship that attend to these goals. For instance, scholars engaged in public scholarship can seek to circulate their research not only through publications but through conferences and public lectures, reports and meetings for community partners, and editorials. Additional avenues for public scholarship include contributions to websites and blogs, exhibitions of creative work, engagement with the media, and utilization of social media and online applications to connect with a broader audience. Public scholarship also includes collaboration, which can occur during the research or creative process through to the many ways in which the results of the collaboration are communicated to the public. Any of these means of research dissemination have the potential to increase the public's engagement with scholarly work, and in turn, enhance education and civic life.

Next, we present a third model for scholarship, social scholarship, which exists at the intersection of public scholarship, open science, and social media. It envisions the role social media might play in enacting open, public scholarship as well as the benefits and challenges of embracing this approach to scholarship today.

\section{Social Scholarship: A Model for Open, Public Scholarship through Social Media}

Building on the central ideas of open science and public scholarship, social scholarship is a recent model for scholarly practices that re-envisions Boyer's (1990) seminal, four-dimensional model for scholarly activities (i.e., scholarship of discovery, teaching, integration, and application) in light of social media advancements [16]. Social scholarship seeks to take advantage of social media affordances (i.e., user-generated content and promotion of users and their interrelationships) and values (i.e., knowledge as accessible, co-constructed, decentralized, and connective) to evolve the ways scholarship is performed in academia. Cohen (2007, paragraph 1, as cited in [1]) defines social scholarship as "the practice $[\ldots]$ in which the use of social tools is an integral part of the research and publishing process ... [and is characterized by] openness, conversation, collaboration, access, sharing and transparent revision." 
Social scholars use social media to publish and interact with scholarly output and to join an online community devoted to their topic [1] (Cohen, 2007, April 5, paragraph 4). "Openness" has typically referred to open data-sharing, open source code, open peer review, or freeing the academic literature from paywalls [4], but with social scholarship, its meaning has broadened to include alternate forms of peer review, public engagement in science, and the recognition of various forms of output as legitimate products of research effort [1].

Social scholarship integrates the use of these social media tools throughout the research and publication process in ways that promote wider access, openness, transparency, and collaboration. For instance, social scholarship advocates informal, social review of articles as a complement to traditional and open science peer review models [4]. In open science peer review, journals publish reviewer reports either as a component of the pre-publication review process or post-publication, where, after editorial review, submitted articles are published online and peer review occurs openly (i.e., reviews with names of reviewers are published by the journal alongside the article and authors are invited to publish revisions in response) [4]. By adding an informal social review process, scholarly work is made openly accessible on social media platform(s) to a broad audience of specialists and non-specialists and undergoes an explicit or implicit review. In explicit review the audience on social media is invited to scrutinize and post or comment on the scholarly work using the social media platform. For example, in the case of the \#arseniclife debate on Twitter, tweets indicated skeptical and non-skeptical views of a scientific article that claimed bacteria could replace phosphorus for arsenic in its genetic material [17]. To back up their claims, Twitter users involved in the \#arseniclife conversation, tweeted links to critiques and studies refuting the original study's central claim, which were published on blogs before publication in traditional academic outlets. Ultimately, the arsenic life hypothesis was dismissed with the open access publication of a study refuting it by one academic blogger. In implicit review, the audience engages with the scholarly work as indicated by metadata (e.g., favoriting, liking, retweeting, sharing, tagging, bookmarking, page views, download numbers, etc.) which can sustain public interest in the research and reveal the extent of connections the work has generated.

Advantages to incorporating informal, social review as part of social scholarship practice are that it may help identify inaccuracies; resurface overlooked research, practice, and policy implications; sustain debates on controversial findings; raise research visibility by engaging journalists; and engage the broader public in cutting edge science [1,2,17]. Furthermore, studies have shown that such informal review can produce higher-quality research with better verified claims [17]. On the other hand, challenges with informal review are that non-specialists, journalists, and social media influencers, or those with outsize followings, can shape conversation in misleading or unwarranted ways, all within public view, and contribute to the spread of misinformation. For a more complete discussion of the practices that make up social scholarship and their benefits and challenges, see [1,2].

In addition to the above example of using Twitter to promote wider access, openness, transparency, and collaboration through social scholarship, other social media such as Facebook and the academic social network sites (Research Gate and Academia.edu) also have the potential to influence open, social scholarly practices. Facebook, for example, has been noted for its ability to enhance scholars' engagement with an open, collaborative research process, and not merely with research outcomes or published research; drawing on their social capital, or the people and information resources available to them in their online social network of Facebook friends, scholars share various types of information, ask for resources, and question a wide and diverse audience about what problems are worth investigating in the first place [18]. As on Twitter, academics on Facebook can engage in formal and informal social review; sustain attention to topics or controversial research; disseminate work quickly to a wide audience; and gain recognition, feedback, and support from peers worldwide [13,18]. On the other hand, critics of the use of Facebook to advance new forms of scholarship point out that Facebook's designed features "constrain their users, fostering 'conviviality and liking' over debate and discussion" (p. 166) because Facebook seeks to control users' attention and behaviors, giving people more of what they like in accord with the targeted advertising on which the platform depends [18]. 
Unlike Facebook and Twitter, social media like ResearchGate and Academia.edu, both for-profit companies founded in 2008, were designed to facilitate academic and research practices and have features that can promote open dissemination practices and knowledge-sharing within academic communities [19]. For instance, ResearchGate supports knowledge-sharing and research dissemination by allowing academics to upload research products, "follow" other academics, and get notified when academics of interest upload new scholarly products. Similar to the aforementioned examples of explicit and implicit social review on other social media platforms, academics on ResearchGate can comment on research publications, and ask and reply to questions with the questions feature. Users can signal their engagement with others' projects and publications, contributing to implicit social review, by viewing, downloading, bookmarking, recommending, following, or sharing the work. These activities are counted and totaled by the platform so that users can see how much interaction the scholarship is generating. Although, in contrast to ResearchGate, Academia.edu is more popular for scholarship in the arts and humanities than in the social sciences, it has similar features for knowledge-sharing, open research dissemination, and social review [19]. Like ResearchGate, users of Academia.edu can upload research artifacts, including a wide range of outputs such as peer-reviewed publications, working drafts, book chapters, conference papers, and teaching material. On "sessions" pages, users can comment on papers or leave line-by-line annotations. Through the "views" feature and through the analytics dashboard on each scholar's profile page, users can see indicators of engagement their work has generated.

However, drawbacks to using these social media platforms for new forms of scholarship have been noted in the literature. One criticism is that site features, such as the analytics dashboard on Academica.edu, reinforce a form of "navel-gazing", incentivizing scholars to constantly self-monitor and self-promote rather than focus their attention on knowledge advancement and dissemination for the collective good [20]. Concerns over the quality and credibility of work openly shared on these sites $[19,21]$, as on Facebook and Twitter $[13,18]$, have also been noted. Perhaps most importantly, the integration of these social tools into scholars' lives is largely uncharted and unexplored territory which may have far-reaching, potentially negative consequences we have yet to understand. A recent review of the literature on ResearchGate and Academia.edu as tools for scholarly communication, for instance, found only two studies that actually investigated scholarly practices when using these academic social network sites [19]; one study examined whether authors comply with publishers' copyright agreements when uploading their articles to ResearchGate [22], and the other examined question-and-answers and small group discussions on ResearchGate [23]. On the other hand, scholars have theorized several advantages to using these academic social network sites for open, social scholarly practices: They help users to keep up with research trends, build communities, and engage in conversation; they improve open sharing of scholarly outputs at various stages; they stimulate alternate formal and informal forms of peer review; and they develop and enhance academic reputation and identity [19].

Thus, social scholarship exists at the intersection of open science, public scholarship, and social media. Although research documenting such new forms of scholarship-in-practice is nascent, social scholarship principles emphasize widening the open review process to encompass informal social review, encouraging scholarship dissemination beyond academic journals platforms as legitimate outlets for research, and changing the dynamics of traditional knowledge production from scholar to consumer toward collaborative knowledge production built on public engagement with research via social media.

\section{Citizen-Scholars}

Whether working from the traditional model of scholarship or the open, public, and social scholarship approaches emerging today, academics, especially those at land-grant universities, have always had the important responsibility of generating and circulating discoveries that advance the 
knowledge base, improve education, and contribute to the public good. Indeed, one of the many purposes of education has long been to produce informed citizens who participate in civic life [24].

Broadly speaking, civic refers to all aspects of life that are related to the communities in which one lives, ranging from one's neighborhood and municipality through to state and national issues and government [24]. Civic responsibility, in turn, refers to the idea that all members of a community bear responsibility for its social and societal problems and are willing to be informed about, and take action regarding, these issues [24]. Citizen-scholars, then, have a civic responsibility to work toward the generation of accessible, shareable, usable scholarship that informs the public and helps address pressing societal problems. Citizen-scholars also have a responsibility to stay up-to-date on their field of study and to engage civically in issues that pertain to their expertise. Although civic engagement has typically referred to conventional ways in which people fulfill their civic duty (e.g., voting) [25], this definition is changing in light of citizens' adoption of social media for civic and political purposes and new models of citizenship today.

For instance, Bennett theorized two citizenship styles in use today: dutiful citizenship and actualizing citizenship [26]. These two models differ in their approaches to civic engagement, sources of information, expressions of civic opinions, and types of civic actions [27]. Dutiful citizenship is the traditional model of citizenship, where civic engagement is an obligation and duty; information comes from legacy news sources such as newspapers and television news, civic expression is done through writing letters to newspapers and through voting, and civic action is related to traditional political party or governmental structure $[27,28]$. In contrast, actualizing citizenship is a more contemporary model. Citizens who hold this style of citizenship see civic engagement as personal; what is "known" is a blend of information and action that has been co-created and co-curated over online social networks. Civic expression occurs over a wide variety of platforms, and civic action includes more fluid membership in online groups, social media movements (e.g., \#BlackLivesMatter, \#MeToo), protests, marches, and consumer boycotts $[27,28]$. In this context, citizen-scholars are poised at the intersection of scholarship trends, social media advancements, and contemporary forms of civic engagement to participate in the public co-curation and co-creation of knowledge, educational innovation and evidence-based solutions to complex problems.

Particularly in this time of "fake news" and "alternative facts," it is critically important for citizen-scholars to contribute to the knowledge and public discourse being shared via social media.

\section{Conclusions}

In this conceptual article, we have explored the benefits and challenges of practicing contemporary approaches to scholarship in service to making research more widely accessible, shareable, and usable in the public sphere. Today's citizen-scholars, perhaps now more than any time in history, have an obligation and an opportunity to utilize powerful, ubiquitous social media platforms to engage the public in science and collective, civic action. The need for informed and educated citizens has not diminished in the age of social media. In the era of "fake news," the distribution and discussion of accurate and timely research is critical, and citizen-scholars, through open, public, and social scholarship, can play a significant role in promoting an informed citizenry.

Author Contributions: Both authors contributed substantially to this work. Both authors contributed to the article's conceptualization, writing — original draft preparation, and writing—review and editing.

Funding: This research received no external funding.

Conflicts of Interest: The authors declare no conflict of interest.

\section{References}

1. Greenhow, C.; Gleason, B. Social scholarship: Reconsidering scholarly practices in the age of social media. Br. J. Educ. Technol. 2014, 45, 392-402. [CrossRef] 
2. Greenhow, C.; Gleason, B. The social scholar: Re-interpreting scholarship in the shifting university. Horizon 2015, 23, 277-284. [CrossRef]

3. Weller, M. The Digital Scholar: How Technology Is Transforming Scholarly Practice; Bloomsbury Academic: London, UK, 2011.

4. Masuzzo, P.; Martens, L. Do You Speak Open Science? Resources and Tips to Learn the Language. PeerJ 2017, in press. [CrossRef]

5. The Open Science Project. An Informal Definition of OpenScience. Available online: http://www. openscience.org/blog/?p=454 (accessed on 22 November 2018).

6. Ioannidis, J.P.; Munafo, M.R.; Fusar-Poli, P.; Nosek, B.A.; David, S.P. Publication and other reporting biases in cognitive sciences: Detection, prevalence, and prevention. Trends Cogn. Sci. 2014, 18, 235-241. [CrossRef] [PubMed]

7. Abeles, T.P. The university-The shifting past. Horizon 2014, 22, 101-109. [CrossRef]

8. Nosek, B.A.; Alter, G.; Banks, G.C.; Borsboom, D.; Bowman, S.D.; Breckler, S.J.; Buck, S.; Chambers, C.D.; Chin, G.; Christensen, G.; et al. Promoting an open research culture. Science 2015, 348, 1422-1425. [CrossRef] [PubMed]

9. Greenhow, C.; Robelia, B.; Hughes, J.E. Learning, teaching, and scholarship in a digital age: Web 2.0 and classroom research: What path should we take now? Educ. Res. 2009, 38, 246-259. [CrossRef]

10. Taylor, M.; Jensen, K.S. Engaging and Supporting a University Press Scholarly Community. Publications 2018, 6, 13. [CrossRef]

11. Hartgerink, C.H.; van Zelst, M. "As-you-go" instead of "after-the-fact": A network approach to scholarly communication and evaluation. Publications 2018, 6, 21. [CrossRef]

12. McKiernan, E.C.; Bourne, P.E.; Brown, C.T.; Buck, S.; Kenall, A.; Lin, J.; McDougall, D.; Nosek, B.A.; Ram, K.; Soderberg, C.K.; et al. How open science helps researchers succeed. eLife 2016, 5, e16800. [CrossRef] [PubMed]

13. Zhu, Y.; Procter, R. Use of blogs, Twitter and Facebook by UK PhD students for scholarly communication. Obs. J. 2015, 9, 29-46.

14. Dewey, J. Democracy and Education: An Introduction to the Philosophy of Education; Dover Publications: Mineola, NY, USA, 2004.

15. Ellison, J.; Eatman, T.K. Scholarship in Public: Knowledge Creation and Tenure Policy in the Engaged University; Imagining America: Syracuse, NY, USA, 2008.

16. Boyer, E.L. Scholarship Reconsidered: Priorities of the Professoriate; Carnegie Foundation for the Advancement of Teaching: Princeton, NJ, USA, 1990.

17. Yeo, S.K.; Liang, X.; Brossard, D.; Ross, K.M.; Korzekwa, K.; Scheufele, D.A.; Xenos, M.A. The case of \#arseniclife: Blogs and twitter in informal peer review. Public Underst. Sci. 2017, 26, 937-952. [PubMed]

18. Manca, A.; Whitworth, A. Social media and workplace practices in higher education institutions: A review. J. Soc. Media Soc. 2018, 7, 151-183.

19. Manca, S. ResearchGate and Academia.edu as networked socio-technical systems for scholarly communication: A literature review. Res. Learn. Technol. 2018, 26, 1-17. [CrossRef]

20. Duffy, B.E.; Pooley, J.D. Facebook for academics: The convergence of self-branding and social media logic on Academia.edu. Soc. Media Soc. 2017, 3, 1-11. [CrossRef]

21. Ovadia, S. ResearchGate and Academia.edu: Academic social networks. Behav. Soc. Sci. Libr. 2014, 33, 165-169. [CrossRef]

22. Jamali, H.R. Copyright compliance and infringement in ResearchGate full-text journal articles. Scientometrics 2017, 112, 241-254. [CrossRef]

23. Jeng, W.; DesAutels, S.; He, D.; Li, L. Information exchange on an academic social networking site: A multi-discipline comparison on ResearchGate Q\&A. J. Assoc. Inf. Sci. Technol. 2017, 68, 638-652.

24. Colby, A.; Ehrlich, T.; Beaumont, E.; Rosner, J.; Stephens, J. Higher education and the development of civic responsibility. In Civic Responsibility and Higher Education; Ehrlich, T., Ed.; The Onyx Press: Westport, CT, USA, 2000; pp. 21-43.

25. Sherrod, L.R.; Torney-Purta, J.; Flanagan, C. Research on the development of citizenship: A field comes of age. In The Handbook of Research on Civic Engagement; Sherrod, L.R., Torney-Purta, J., Flanagan, C., Eds.; John Wiley \& Sons: Hoboken, NJ, USA, 2010; pp. 1-20. 
26. Bennett, W.L. Changing citizenship in the digital age. In Civic Life Online: Learning How Digital Media Can Engage Youth; Bennett, W.L., Ed.; The MIT Press: Cambridge, MA, USA, 2008; pp. 1-24.

27. Bennett, W.L.; Freelon, D.; Wells, C. Changing citizen identity and the rise of a participatory media culture. In The Handbook of Research on Civic Engagement; Sherrod, L.R., Torney-Purta, J., Flanagan, C., Eds.; John Wiley \& Sons: Hoboken, NJ, USA, 2010; pp. 393-423.

28. Bennett, W.L.; Wells, C.; Rank, A. Young citizens and civic learning: Two paradigms of citizenship in the digital age. Citizsh. Stud. 2009, 13, 105-120. [CrossRef]

(C) 2019 by the authors. Licensee MDPI, Basel, Switzerland. This article is an open access article distributed under the terms and conditions of the Creative Commons Attribution (CC BY) license (http:/ / creativecommons.org/licenses/by/4.0/). 